\title{
Avaliação da incorporação do lodo de Estação de Tratamento de Água em peças de concreto intertravado
}

\section{Study of water treatment sludge incorporation into interlocking concrete pavers}

Lucas Plattner Fernandez ${ }^{1}$, Paula Cristina Buss Mikowski ${ }^{1}$, Gustavo Macioski ${ }^{2}$, André Nagalli ${ }^{3}$, Flavio Bentes Freire ${ }^{3}$

\footnotetext{
${ }^{1}$ Departamento Acadêmico de Construção Civil - DACOC/UTFPR, CEP: 81.280-340, Curitiba, Paraná, Brasil.

${ }^{2}$ Programa de Pós-Graduação em Construção Civil - PPGECC/UFPR, CEP: 81.531-980, Curitiba, Paraná, Brasil.

${ }^{3}$ Programa de Pós-Graduação em Engenharia Civil - PPGEC/UTFPR, CEP: 81.280-340, Curitiba, Paraná, Brasil. e-mail: lucasplattner@gmail.com, paulacbmikowski@gmail.com,gmacioski@gmail.com, nagalliutfpr@gmail.com, freireutfpr@gmail.com
}

\begin{abstract}
RESUMO
O lodo gerado nas estações de tratamento de água é resultado de várias operações que visam adequação da água aos padrões legais de potabilidade. Apesar de haver alternativas para o tratamento do lodo, as soluções de disposição final usualmente empregadas como descarte direto em cursos d'água, ainda representam grandes impactos e sobrecarregam os sistemas envolvidos. O presente trabalho tem como objetivo avaliar a viabilidade técnica da incorporação de lodo de uma estação de tratamento de água na produção de peças de concreto para pavimentação intertravada. Foi avaliada a influência da umidade do lodo no comportamento do concreto. As peças de concreto para pavimentação intertravada com teores em relação a massa de cimento de 2,5\%, 5,0\% e 7,5\% de lodo no estado natural e 5,0\% de lodo seco em estufa foram avaliadas por meio de ensaios de resistência à compressão axial, resistência à tração na flexão, índice de vazios, absorção de água e massa específica. Com os resultados obtidos comprovou-se que teores de até 5,0\% de adição não geram alterações significativas nas propriedades do concreto. Portanto, seria viável a adição do lodo de estações de tratamento de água em peças de concreto para pavimentação intertravada, desde que limitada a teores baixos. A incorporação de resíduos industriais em materiais de construção se mostra uma alternativa viável para minimizar o passivo ambiental resultante de processos de produção e tratamento de outros materiais.
\end{abstract}

Palavras-chave: Lodo, Estação de tratamento de Água, Concreto.

\section{ABSTRACT}

The sludge generated in the water treatment plants is the result of several operations that aim the adequacy of water to the legal standards of potability. Although there are alternatives for water treatment sludge, the usual final disposal solutions, as direct discharge into watercourses, still represent large impacts and overload the systems involved. The present paper aims to evaluate the technical viability of the incorporation of sludge from water treatment plants into interlocking concrete pavers. The influence of sludge moisture on the concrete behavior was also evaluated. Interlocking concrete pavers with cement mass contents of $2.5 \%, 5.0 \%$ and $7.5 \%$ of sludge at its natural moisture and $5.0 \%$ of dried sludge were evaluated by tests of compression strength, tensile strength by flexion, voids index, water absorption and density. The results showed that contents of up to $5.0 \%$ of addition do not generate significant changes in the properties of the concrete. Therefore, it would be possible to add sludge from water treatment plants in on interlocking concrete pavers, since limited to low levels. The incorporation of industrial waste into building materials is a viable alternative to minimize the environmental liabilities resulting from processes of production and treatment of other materials.

Keywords: Waste, Water treatment plant, Concrete. 


\section{INTRODUÇÃO}

O crescimento populacional resultou no aumento do consumo de água potável e na consequente elevação da quantidade de rejeitos gerados nas Estações de Tratamento de Água (ETA). A NBR 10004 [1] classifica o lodo de ETA como resíduo sólido, que deve ser tratado, reutilizado e/ou reciclado, proibindo o seu lançamento in natura nos corpos d'água. Já a Lei 6.938 de 1981 institui o descarte de lodo em cursos d'água como crime ambiental [2]. Portanto, faz-se necessária uma política adequada de destinação destes resíduos.

Embora existam alternativas de tratamento para o lodo, grande número de estações de tratamento de água ainda faz o descarte inadequado desses resíduos. BARROSO [3] expõe que, no Brasil, menos de 0,5\% das estações de tratamento de água possuíam, até o ano de 2007, sistemas de secagem do lodo. Quando lançado diretamente em córregos e rios, o lodo afeta o corpo receptor, comprometendo a qualidade da água. Em outros casos, o lodo é disposto em aterros sanitários ou encaminhado para as estações de tratamento de esgoto, podendo causar problemas operacionais e transferindo, dessa forma, o problema de disposição [4].

De acordo com HOPPEN et al. [5], no Paraná eram produzidos em 2006 aproximadamente 4000 t/mês em matéria seca de lodo de estações de tratamento de água, sendo mais de 50\% da região de Curitiba. CARNEIRO et al. [6], afirmaram ainda que a produção de lodo no Paraná em 2011 era de cerca de 118 mil litros por dia; sendo que apenas $18,2 \%$ das estações de tratamento de água possuíam alguma metodologia para o desaguamento.

A busca por soluções técnica e economicamente viáveis, bem como ambientalmente coerentes, representa uma oportunidade de reduzir impactos associados a este resíduo. Dentre as possibilidades de reutilização ou destinação final dos rejeitos de estações de tratamento de água, existe a possibilidade de aplicação em materiais de construção civil. Os sólidos resultantes do tratamento realizado nas ETAs podem ser incorporados em concreto, aplicados em cerâmicas ou utilizados para outras finalidades, se conhecidas as suas propriedades e seus potenciais usos [3].

Além disso, a indústria da construção civil é uma das principais responsáveis pela extração e utilização dos recursos naturais para a fabricação de materiais. De uma maneira geral, os processos de fabricação dos materiais tradicionais se caracterizam por ações agressivas sobre o meio ambiente. A busca por soluções ambientalmente responsáveis faz, portanto, ainda mais importante o desenvolvimento de materiais com a incorporação de resíduos e baseados em matérias-primas alternativas, que reduzam o consumo de materiais associados a grandes impactos ambientais.

Sendo assim, a incorporação do lodo de ETA no concreto, alia a necessidade de uma nova forma de destinação deste resíduo à necessidade da indústria da construção civil por novas matérias primas. Dessa forma, o objetivo deste trabalho é analisar a viabilidade técnica da utilização de lodo resultante do tratamento de água em ETA no processo de fabricação de peças de concreto para pavimentação intertravada.

\section{MATERIAIS E MÉTODOS}

Nesta seção são apresentadas as metodologias empregadas para e coleta de amostras do lodo, caracterização físico-química do material, processos de oxidação realizados, dosagem do concreto e avaliação das propriedades do concreto no estado endurecido.

\subsection{Coleta e caracterização do lodo}

O lodo utilizado nesta pesquisa é proveniente da ETA Passaúna, operada pela SANEPAR, localizada na região metropolitana de Curitiba. A ETA utiliza como coagulante o sulfato de alumínio e trata uma vazão aproximada de $1.800 \mathrm{~L} / \mathrm{s}$. Para a pesquisa foi realizada a coleta do lodo centrifugado, que permaneceu armazenado em bombonas de polietileno de alta densidade (PEAD).

Com o objetivo de avaliar a influência do lodo na dosagem e trabalhabilidade do concreto, realizou-se a caracterização físico-química do lodo. As análises do $\mathrm{pH}$, sólidos totais, sólidos voláteis e sólidos fixos seguiram metodologias descritas no Standard Methods for Examination of Waterand Waste water[7]. Também foram realizados ensaios de umidade [8], massa específica [9] e perda ao fogo [10].

A análise química foi feita por espectroscopia de fluorescência de raio $\mathrm{X}$ por energia dispersiva (EDX-720/800 HS, SHIMADZU), que utilizou um tubo de Ródio e um detector de $\mathrm{Si}(\mathrm{Li}$ ) operando à $50 \mathrm{kV}$, sendo que os valores da composição química foram normalizados pela perda ao fogo. A análise da cristalografia foi realizada em um difratômetro de raios X (XRD-7000, SHIMATZU). Os parâmetros de ensaio foram: ângulo de $5^{\circ}$ a $75^{\circ}$, passo de $0,02^{\circ}$, velocidade de varredura de $2^{\circ} / \mathrm{min}$. A indexação dos compostos foi realizada no software X'PertHighscore, com banco de dados cristalográficos do ICDD (International Centre for Diffraction Data) de 2003. 


\subsection{Materiais utilizados, dosagem e caracterização do concreto}

Para dosagem dos traços de concreto foi utilizado cimento Portland CPV-ARI com densidade de 3,09 g/ $\mathrm{cm}^{3}$, por não apresentar adições minerais que poderiam interagir com o lodo e pelo rápido período de desmoldagem. Utilizou-se agregado miúdo natural de rio com módulo de finura igual a 2,21 e agregado graúdo granítico com dimensão máxima característica de $9,5 \mathrm{~mm}$. A caracterização destes agregados é apresentada na Tabela 1 e a distribuição granulométrica dos agregados é apresentada na Figura 1.

Tabela 1: Caracterização dos agregados.

\begin{tabular}{llll}
\hline PARÂMETRO & AGREGADO MIÚDO & AGREGADO GRAÚDO & NORMATIVA \\
\hline Massa específica & $2,57 \mathrm{~g} / \mathrm{cm}^{3}$ & $2,81 \mathrm{~g} / \mathrm{cm}^{3}$ & {$[9,13]$} \\
\hline Massa unitária & $1,44 \mathrm{~g} / \mathrm{cm}^{3}$ & $1,35 \mathrm{~g} / \mathrm{cm}^{3}$ & {$[14]$} \\
\hline Massa unitária compactada & $1,60 \mathrm{~g} / \mathrm{cm}^{3}$ & $1,52 \mathrm{~g} / \mathrm{cm}^{3}$ & {$[14]$} \\
\hline Absorção & $1,06 \%$ & $2,30 \%$ & {$[13,15]$} \\
\hline Material pulverulento & $2,24 \%$ & $0,94 \%$ & {$[16]$} \\
\hline Índice de vazios & Não se aplica & $5,96 \%$ & {$[14]$} \\
\hline
\end{tabular}
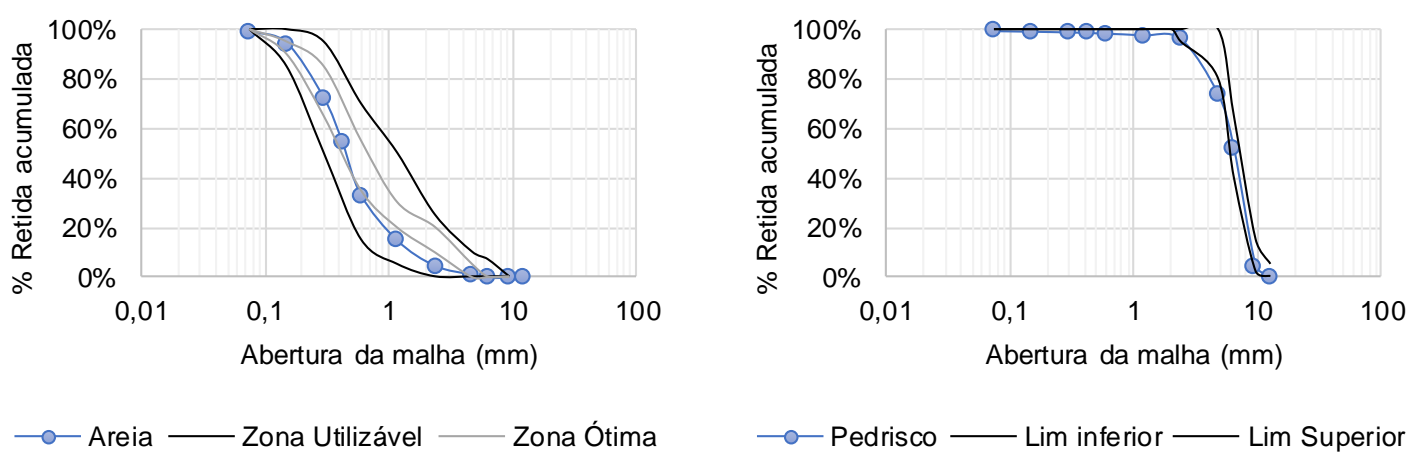

Figura 1: Distribuição granulométrica dos agregados.

A dosagem do concreto convencional foi realizada pelo método ABCP/ACI e levou em consideração a resistência característica exigida pela NBR 9781 [17]. Na Tabela 2 são apresentados os parâmetros obtidos pelo método de dosagem.

Tabela 2: Dosagem do concreto

\begin{tabular}{ll}
\hline PARÂMETRO & VALOR \\
\hline $\mathrm{f}_{\mathrm{cj}}$ & $33,53 \mathrm{MPa}$ \\
\hline Relação a/c & 0,59 \\
\hline Consumo de cimento & $381 \mathrm{~kg} / \mathrm{m}^{3}$ \\
\hline Consumo de agregado miúdo & $834 \mathrm{~g} / \mathrm{cm}^{3}$ \\
\hline Consumo de agregado graúdo & $920 \mathrm{~g} / \mathrm{cm}^{3}$ \\
\hline Consumo de água & $225 \mathrm{~kg} / \mathrm{m}^{3}$ \\
\hline
\end{tabular}

Foram realizadas adições de lodo de ETA úmido nos teores de 2,5\%, 5,0\% e 7,5\% em relação à massa de cimento, com correção da umidade das amostras com base na umidade do resíduo. Quando necessário ajustar a trabalhabilidade (fixada em $60 \mathrm{~mm}$ no ensaio de abatimento de tronco de cone), foi utilizado o aditivo superplastificante MC POWERFLOW 1102 de densidade 1,07 g/cm³ de forma a manter a relação a/c.

Foi realizada a moldagem de amostras prismáticas de $(60 \times 100 \times 200) \mathrm{mm}$ em duas camadas e 30 golpes. As amostras foram desmoldadas após $24 \mathrm{~h}$ e permaneceram em cura submersa até os 28 dias. As amostras foram ensaiadas por meio da avaliação da resistência mecânica à compressão [17], resistência à tração por flexão [18] em uma máquina de ensaios universal (DL 30.000, EMIC). Também foram realizados ensaios de 
absorção, índice de vazios e massa específica de acordo com a NBR 9778 [19].

\section{RESULTADOS E DISCUSSÃO}

\subsection{Caracterização do lodo}

Após caracterização do lodo de ETA coletado, foi possível a análise e comparação dos resultados obtidos. Na Tabela 3 são apresentados os valores encontrados.

Tabela 3: Caracterização do lodo

\begin{tabular}{ll}
\hline PARÂMETRO & VALOR \\
\hline $\mathrm{pH}$ & 6,97 \\
\hline Massa específica & $1,74 \mathrm{~g} / \mathrm{cm}^{3}$ \\
\hline Teor de umidade & $87,4 \%$ \\
\hline Sólidos totais & $12,8 \%$ \\
\hline Sólidos voláteis & $35,7 \%$ \\
\hline Sólidos fixos & $64,4 \%$ \\
\hline
\end{tabular}

$\mathrm{O}$ valor obtido para o pH encontra-se bastante próximo à neutralidade, estando dentro do intervalo de 6 a 8 proposto por RICHTER [20], para lodos provenientes do tratamento de água com sulfato de alumínio. Este valor também se encontra bastante próximo a média de 6,73 obtida na caracterização do lodo da ETA Passaúna realizada por PORTELLA et al. [21]. Este valor está dentro do valor de tolerância, especificado entre 5,5 e 9,0, estabelecido pela NBR NM 137 [22] para a água de amassamento na produção de concreto.

O valor obtido da massa específica seca foi de $1,73 \mathrm{~g} / \mathrm{cm}^{3}$, estando próximo ao valor médio de 1,80 $\mathrm{g} / \mathrm{cm}^{3}$, recomendado por RICHTER [20] para cálculos estimativos de volume. Em comparação aos demais materiais utilizados no concreto $-3,09 \mathrm{~g} / \mathrm{cm}^{3}$ para o cimento; $2,57 \mathrm{~g} / \mathrm{cm}^{3}$ para o agregado miúdo e $2,81 \mathrm{~g} / \mathrm{cm}^{3}$ para agregado graúdo, o lodo apresenta massa específica inferior. Sendo assim, a sua adição no concreto pode representar uma leve redução na massa especifica do concreto.

O teor de umidade médio de $87,4 \%$ é similar aos valores obtidos em outras caracterizações do lodo da ETA Passaúna: 86,9\% [21]; 88,1\% [23] e 86,4\% [24]. O conhecimento deste valor foi de extrema importância para a dosagem adequada dos materiais, principalmente em relação a correção da quantidade de água nos traços com adição de lodo úmido. Devido ao alto teor de umidade do lodo, verificou-se pela dosagem realizada, não ser possível a adição de teores superiores a $8 \%$.

O teor de ST de 12,8\% está abaixo dos valores de referência de 15 a 35\% característicos após o desaguamento do lodo em centrifuga [25], possivelmente decorrentes de variações pelo equipamento utilizado neste processo. No entanto está similar ao valor de ST de 11,9\% determinado por HOPPEN et al.[23] em caracterização anterior.

Relacionados à porção de matéria orgânica, BIDONE et al. [26] atribuem uma concentração característica de 20 a $35 \%$ para o teor de SV em lodos de ETA, tendo sido obtido nesta pesquisa o valor médio de $35,7 \%$, enquanto Oliveira [25] obteve uma média de 37\% de SV. Para o teor de SF foi obtida uma média de $64,4 \%$, muito próximo ao valor de $63,2 \%$ obtido por OLIVEIRA [25].

Após a realização do ensaio de perda ao fogo e de análise química por espectroscopia de fluorescência de raios $\mathrm{X}$ por energia dispersiva foram obtidos os resultados de composição química apresentados na Tabela 4. Detecção de traços de elementos com concentração inferior à $0,1 \%$ foram suprimidos.

Tabela 4: Composição química do lodo em teor de óxidos

\begin{tabular}{lllllllll}
\hline $\mathrm{Al}_{2} \mathrm{O}_{3}$ & $\mathrm{SiO}_{2}$ & $\mathrm{SO}_{3}$ & $\mathrm{CaO}$ & $\mathrm{Fe}_{2} \mathrm{O}_{3}$ & $\mathrm{TiO}_{2}$ & $\mathrm{MnO}$ & P.F. & Total \\
\hline $33,98 \%$ & $18,56 \%$ & $3,60 \%$ & $0,63 \%$ & $0,62 \%$ & $0,12 \%$ & $0,09 \%$ & $42,40 \%$ & $100,00 \%$ \\
\hline
\end{tabular}

$\mathrm{O}$ valor mais expressivo observado é relacionado ao $\mathrm{Al}_{2} \mathrm{O}_{3}$, em uma porcentagem de 33,98\%, equivalente a valores encontrados na literatura para lodos oriundos de processos com sulfato de alumínio como coagulante, como a média de 22,21\% obtida por PORTELLA et al. [21]. A quantidade de 18,56\% determinada 
para $\mathrm{SiO}_{2}$ pode estar relacionada a presença de materiais argilosos e sílica da areia na água bruta, havendo sido obtido uma média de $13,43 \%$ por PORTELLA et al. [21].

A porcentagem de $0,62 \%$ de $\mathrm{Fe}_{2} \mathrm{O}_{3}$ difere-se de valores obtidos na pesquisa realizada por PORTELLA et al. [21], na qual a concentração média de $\mathrm{Fe}_{2} \mathrm{O}_{3}$ identificada foi de 7,99\%. Verificando-se os relatórios de caracterização fornecidos pela SANEPAR pode se observar também divergências nas concentrações de ferro (mg/L de $\left.\mathrm{Fe}^{-}\right)$no extrato solubilizado de análises realizadas em diferentes períodos: variando de 26,6a 0,84 entre 2014 e 2016. Essa divergência pode ser explicada por possíveis variações nos produtos utilizados no processo de tratamento de água, bem como pela maior concentração de hidróxidos de ferro em solos muito intemperizados [27]. Pelo fato de haverem variações no lodo em decorrências da sazonalidade e das características do manancial, o período de coleta influencia em sua composição.

Os compostos $\mathrm{Al}_{2} \mathrm{O}_{3}, \mathrm{SiO}_{2}$ e o $\mathrm{Fe}_{2} \mathrm{O}_{3}$ presentes no lodo, são também encontrados na composição do cimento, assim como o $\mathrm{CaO}$ [20]. A presença destes elementos no lodo pode, portanto, influenciar nas reações de hidratação do cimento, por se associarem a outros compostos para a formação do concreto. A presença de $\mathrm{SO}_{3}$, por outro lado, pode gerar condições para o ataque de sulfatos ao concreto, com a formação de cristais expansivos que causam tensões no interior da argamassa, facilitando a ruptura e influenciando na durabilidade deste material [28].

Em relação à perda ao fogo, a média obtida de $42,4 \%$, fazendo-se a calcinação a $1000^{\circ} \mathrm{C}$ em mufla, foi próximo à média de 49,8\% obtida por HOPPEN et al. [23], e de 50,1\% obtida por e PORTELLA et al. [21]. A perda ao fogo expressa a redução de massa que pode ocorrer devido à desidratação de materiais argilosos, decomposição de materiais carbonáceos e queima de material orgânico da amostra pela perda de hidroxilas estruturais, podendo haver variação dependendo da composição química e das matérias orgânicas presentes no lodo [24]. Na Figura 2 é apresentado o resultado do ensaio de difratometria.

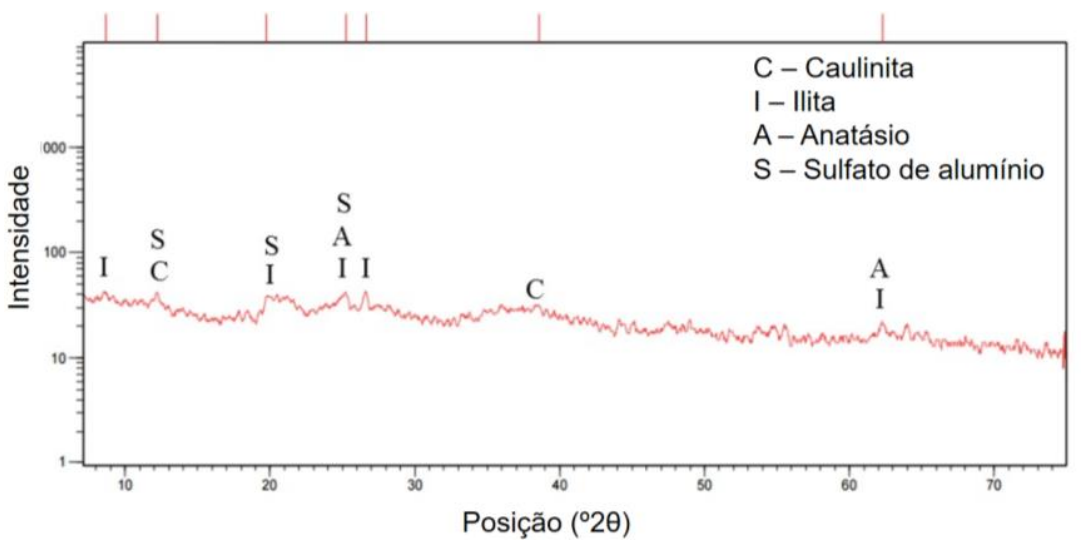

Figura 2: Difratometria de raios $\mathrm{X}$ do lodo.

A partir do resultado de difratometria de raios $\mathrm{X}$ foi possível a verificação de que o lodo se apresenta como uma estrutura amorfa, com baixa cristalinidade. A alta presença de matéria orgânica também está associada à dissipação do raio $\mathrm{X}$ durante o ensaio, impedindo a formação de picos bem definidos. A indexação de picos, mesmo que em baixa intensidade, permitiu a identificação de estruturas como a da caulinita, ilita, anatásio e sulfato de alumínio (Figura 2), semelhante ao observado por PAIXÃO et al. [30]. A presença de sulfato de alumínio é esperada no material por este composto ser utilizado como coagulante no sistema. Os argilominerais ilita, caulinita e anatásio estão associados à presença de solo no conteúdo do solo como suspeitado na análise química. MEDEIROS et. al.[31] atribuem reatividade a estes argilominerais que, na presença do cimento Portland, possuem a capacidade de se comportar como pozolanas. Interagindo, desta forma, com o hidróxido de cálcio remanescente das reações de hidratação deste aglomerante.

\subsection{Propriedades do concreto}

No estado fresco, observou-se que devido aos altos teores de água do lodo, alguns traços apresentaram consistência seca. Esta consistência do concreto produzido com o lodo úmido se justifica pelo fato da viscosidade irregular do lodo impedir a suspensão de maneira uniforme e homogênea das partículas sólidas [3] durante o processo de hidratação do cimento.

Dessa forma, a água incorporada ao lodo não estava disponível para envolvimento dos grãos dos agre- 
gados e do cimento, assim como a água livre. Devido à necessidade de manutenção da relação entre água e cimento, não foi utilizada água livre em quantidade suficiente para adquirir uma melhor trabalhabilidade. Neste sentido, foi necessária a utilização de aditivos superplastificantes para melhor controle da consistência do concreto.

No estado endurecido foram avaliadas as propriedades de resistência à compressão e de tração por flexão, como apresentados na Figura 3.

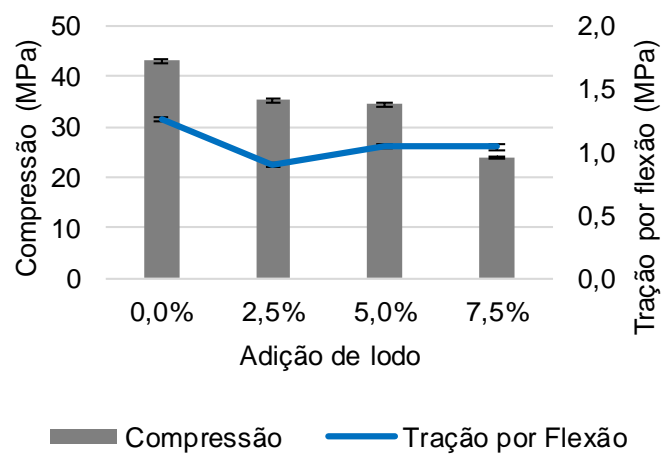

Figura 3: Resistência mecânica das amostras

A partir dos valores apresentados na Figura 3 fica claro que o traço com adição de 2,5\% de lodo, tem um valor de resistência à compressão médio $17,83 \%$ inferior ao concreto de referência e os traços com adição de $5,0 \%$ e $7,5 \%$ de lodo têm redução de, respectivamente, 20,06\% e 44,43\%.

Após teste de variância, infere-se que o teor de lodo influenciou nos resultados de resistência à compressão axial $(\mathrm{p}=0,00003)$. Sendo que, após comparação múltipla de médias pelo método de Tukey observouse que não existe diferença estatisticamente significativa para os teores de 2,5 e $5 \%$.

O teor de 2,5\% de adição de lodo está de acordo com o valor mínimo de resistência à compressão, que é de $35 \mathrm{MPa}$ para peças de concreto para usos comuns, enquanto os teores de 2,5 e 5\% de lodo apresentam valores ligeiramente inferiores ao mínimo requerido.

Estes dados estão alinhados com os obtidos nos estudos de HOPPEN [29], nos quais os valores de resistência à compressão mais próximos ao traço de referência foram os dos traços com adição de 3,0\% e 5,0\% de lodo. Ainda, segundo KAOSOL [32], os valores de resistência à compressão dos traços com adições de lodo de ETA superiores a $10 \%$ apresentam valores significativamente inferiores ao traço padrão, apresentando reduções de resistência a partir de $38,33 \%$.

Quanto aos resultados de tração por flexão, observou-se um comportamento semelhante. A partir dos valores apresentados pela linha azul observa-se que o traço com adição de 2,5\% de lodo, tem um valor de resistência à tração na flexão médio $28,57 \%$ inferior ao concreto de referência e os traços com adição de $5,0 \%$ e $7,5 \%$ de lodo têm redução de, respectivamente, $16,67 \%$ e 17,46\%. Após teste ANOVA confirmou-se a influência do teor de lodo na resistência à compressão, sem diferença estatística para as amostras com 5 e $7,5 \%$ de adição.

Os resultados estão na mesma faixa dos valores obtidos nos estudos de HOPPEN et al. [23], que verificaram uma redução média de $27,38 \%$ para teores de substituição de areia por lodo de $4,0 \%$ e $8,0 \%$, e uma redução de $3,5 \%$ com o incremento em $4 \%$ da quantidade de lodo utilizada.

Uma das hipóteses para explicar a menor queda na tração na flexão com o incremento de lodo adicionado ao concreto é uma possível reação de aluminosilicatos presentes no lodo com o hidróxido de cálcio do cimento Portland [31], agindo de forma mais efetiva nos poros interconectados, permitindo, desta forma, um efeito semelhante à uma fibra.

Com relação aos demais ensaios, não foram observadas alterações significativas nas propriedades do concreto no estado endurecido em função do teor de adição de lodo. Em média, as amostras apresentaram densidades variando de 2,35 a 2,49 g/ $\mathrm{cm}^{3}$, absorção de 2,94 a 3,77\% e índice de vazios de 6,45 a 8,4, como apresentado na Tabela 5 . 
Tabela 5: Propriedades dos concretos no estado endurecido em função do teor de lodo

\begin{tabular}{lllll}
\hline PARÂMETRO/TEOR DE ADIÇÃO & $\mathbf{0 \%}$ & $\mathbf{2 , 5 \%}$ & $\mathbf{5 \%}$ & $\mathbf{7 , 5 \%}$ \\
\hline Densidade $\left(\mathrm{g} / \mathrm{cm}^{3}\right)$ & 2,48 & 2,36 & 2,42 & 2,43 \\
\hline Absorção $(\%)$ & 2,94 & 3,64 & 3,35 & 3,77 \\
\hline Índice de vazios $(\%)$ & 6,45 & 7,87 & 7,49 & 8,40 \\
\hline
\end{tabular}

A partir dos dados da Tabela 5, conclui-se que de forma geral a adição de lodo causou redução da densidade, aumento da absorção e do índice de vazios das peças. BENLALLA et al. [33] e KIZINIEVIČ et al. [35], apesar de tratarem de materiais cerâmicos, notaram a mesma tendência de aumento do índice de vazios a medida que se incorpora lodo. Já HOPPEN [29], com enfoque na produção de concreto com lodo incorporado, obteve incrementos de até $7 \%$ quando substituiu areia por lodo.

Os valores obtidos por TAFAREL et al. [24] para absorção de água apresentaram a mesma tendência de crescimento com adição de lodo nos traços. HOPPEN [29] obteve aumentos de 8,68\% a 25,21\% para a substituição de 3\% a $10 \%$ da areia por lodo. Para materiais cerâmicos, a tendência é também o aumento da absorção de água, porém apenas a partir de elevados teores de adição de lodo [33,34].

Além disso, os valores de absorção de água apresentados na Tabela 5 cumprem as exigências da NBR9781 [17], que estabelece como 7,0\% o limite máximo de absorção de água de uma peça de concreto para pavimentação intertravada. Todas as amostras ensaiadas cumpriram com boa margem esta exigência.

Já os valores de massa específica foram reduzidos em até 5,62\%, em comparação à amostra de referência. Observando comportamento similar em seus estudos, HOPPEN [23] justificou este ocorrido pelo fato de massa específica do lodo ser inferior a dos demais materiais utilizados na produção do concreto. Na Figura 5 são apresentadas as correlações dos ensaios das amostras no estado endurecido.

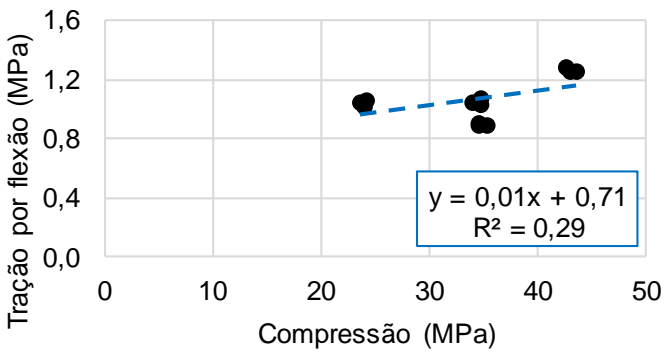

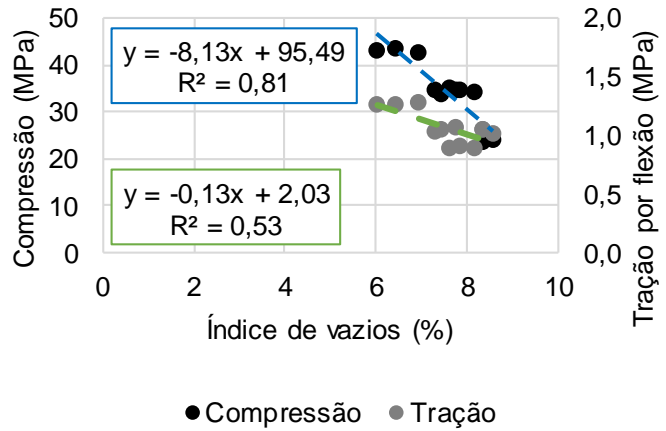

(b)

Figura 4: Correlações obtidas nos ensaios de (a) resistência mecânica e (b) índice de vazios

Segundo MEHTA e MONTEIRO [35] os valores de resistência à tração na flexão correspondem a aproximadamente $10 \%$ dos valores de resistência à compressão. Entretanto, nenhum dos valores obtidos, até mesmo o do traço de referência, apresentaram relação próxima à da literatura, como pode ser observado na Figura 4a. Assim, mesmo com uma tendência de aumento da resistência à tração na flexão com o aumento da resistência à compressão, as variáveis apresentaram baixa correlação entre si $\left(R^{2}=0,29\right)$, em especial devido aos resultados obtidos com o teor de $5 \%$ de incorporação de lodo.

Também se buscou a correlação das resistências mecânicas com o índice de vazios da peça (Figura 5b), uma vez que, a presença de vazios tenderia a falhas de continuidade na amostra e consequente influência no desempenho mecânico. Nota-se, na Figura 4b, que as correlações encontradas foram ainda baixas $\left(\mathrm{R}^{2}=0,81\right.$ para compressão e $\mathrm{R}^{2}=0,53$ para tração na flexão), mas comprova-se a tendência de redução da resistência com o aumento no teor de vazios as peças. É possível estabelecer que a resistência à compressão sofre uma maior influência desta variável, uma vez que esta apresentou um coeficiente angular de correlação mais acentuado. 


\section{CONCLUSÕES}

Os resultados obtidos pelos ensaios das caracterizações do lodo permitiram concluir que o lodo centrifugado possui $\mathrm{pH}$ próximo da neutralidade, podendo ser incorporado ao concreto sem interferir na sua alcalinidade. A alta umidade, mesmo após a centrifugação, limita o teor de incorporação do lodo de ETA no concreto sem tratamentos prévios de secagem, a valores inferiores a $8 \%$ para não ultrapassar a quantidade de água de amassamento determinada na dosagem realizada. As análises químicas e a verificação dos relatórios de caracterização identificaram uma série de compostos inorgânicos e orgânicos que podem influenciar as reações de hidratação do cimento, podendo interferir em parâmetros de durabilidade, bem como interferir nas reações relacionadas a oxidação do lodo.

Há redução na resistência à compressão conforme o aumento do teor de lodo adicionado. Observou-se que o índice de 2,5\% de lodo adicionado atende os requisitos da NBR 9781 [17] e os índices de 5,0\% de lodo úmido e 5,0\% de lodo seco apresentam valores muito próximos ao exigido pela normatização. Houve redução na resistência, em comparação ao concreto de referência de 17,83\% para incorporação de 2,5\% de lodo, $20,06 \%$ para $5 \%$ e $44,43 \%$ para $7,5 \%$. Com o lodo seco, adicionado num teor de $5 \%$, há uma redução relativa de $23,79 \%$.

Também se observou queda na resistência à tração na flexão com a incorporação de lodo. A resistência à tração na flexão apresentou perda de $28,57 \%$ na adição de $2,5 \%$, e de, respectivamente, $16,67 \%$ e $17,46 \%$ para os teores de $5 \%$ e de $7,5 \%$. Já esta redução para a adição de $5,0 \%$ de lodo seco, quando em comparação ao traço de referência, foi de $26,98 \%$.

Houve aumento no índice de vazios em todas as amostras ensaiadas. Para o teor de 2,5\% de lodo adicionado este valor foi de $22,01 \%$, para o de $5,0 \%$ foi de $16,12 \%$ e para o de $7,5 \%$ foi de $30,23 \%$. Já para o caso do lodo seco, o teor de 5,0\% acarretou num acréscimo de 20,47\% no índice de vazios.

Para os traços de 2,5\%, 5,0\% e 7,5\% de adição de lodo úmido, houve aumento de respectivamente $23,81 \%, 13,95 \%$ e 28,23 nos valores de absorção de água. Já para o teor de 5,0\% de lodo seco, este incremento foi de $23,13 \%$. Mesmo com esse aumento, todas as amostras ensaiadas seguiram as exigências da NBR 9781 [17] quanto à absorção de água.

Já a massa específica reduziu com a adição de lodo. O traço com adição de $2,5 \%$ de lodo teve redução de $5,62 \%$, o traço com adição de $5,0 \%$ teve redução de $3,21 \%$ e o traço com adição de 7,5\% teve redução de $2,41 \%$. Já o traço com adição de $5,0 \%$ de lodo seco teve redução de $1,61 \%$.

Quanto a secagem prévia do lodo para a adição no concreto, observou-se, em relação à moldagem das amostras uma melhor trabalhabilidade comparando-se ao lodo úmido adicionado. Comparando-se os resultados das resistências à compressão e à tração na flexão, notou-se ligeira queda, quando comparado ao mesmo teor de lodo úmido. Já para o índice de vazios, absorção de água e massa específica, não foram observados incrementos ou mudanças significativas.

Levando em consideração os resultados, bem como as condições de dosagem e moldagem, constata-se que a adição do lodo em teores de até $5 \%$ é viável na fabricação de peças de concreto para pavimento intertravado. Acima desse teor verifica-se o comprometimento das propriedades técnicas do concreto endurecido e da trabalhabilidade do concreto fresco. Além disso, para o traço de referência determinado, teores acima de 8\% são inviáveis para a adição de lodo úmido, pelo fato de a quantidade de água presente no lodo ser superior a água de amassamento determinada na dosagem do traço.

\section{BIBLIOGRAFIA}

[1] ASSOCIAÇÃO BRASILEIRA DE NORMAS TÉCNICAS. NBR 10004 - Resíduos Sólidos: Classificação. Rio de Janeiro, 2004.

[2] BRASIL. Lei no 6.938 de 3 de agosto de 1981. Dispõe sobre a Política Nacional do Meio Ambiente, seus fins e mecanismos de formulação e aplicação, Brasília, DF, 1981.

[3] BARROSO, M. M. Influência das Micro e Macropropriedades dos Lodos de Estações de Tratamento de Águas no Desaguamento por Leito de Drenagem, Universidade de São Paulo, 2007.

[4] KATAYAMA, V. T. Quantificação da Produção de Lodo de Estações de Tratamento de Água de Ciclo Completo: Uma Análise Crítica, Universidade de São Paulo, 2012.

[5] HOPPEN, C., PORTELLA, K.F., JOUKOSKI, A., et al., "Uso de Lodo de Estação de Tratamento de Água Centrifugado em Matriz de Concreto de Cimento Portland Para Reduzir o Impacto Ambiental", Química Nova, v. 29, n. 1, p. 79-84, 2006. 
[6] CARNEIRO, C., WEBER, P. S., ROSS, B. Z. L., et al., Caracterização de Lodo de ETA gerado no Estado do Paraná In: Lodo de Estações de Tratamento de Água - Gestão e Perspectivas Tecnológicas. Cap. 3, p. 132 - 178. Curitiba, SANEPAR, 2013.

[7] EATON, A. D., CLESCERI, L. S., GREENBERG, A. E. Standard methods for the examination of water and wastewater, 20th ed. Washington, American Public Health Association, 1999.

[8] ASSOCIAÇÃO BRASILEIRA DE NORMAS TÉCNICAS. NBR 6457 - Preparação para ensaios de compactação e ensaios de caracterização. Rio de Janeiro, 1986.

[9] ASSOCIAÇÃO BRASILEIRA DE NORMAS TÉCNICAS. NBR NM 52 - Agregado miúdo - Determinação da massa específica e massa específica aparente. Rio de Janeiro, 2009.

[10] ASSOCIAÇÃO BRASILEIRA DE NORMAS TÉCNICAS. NBR NM 18 - Cimento Portland - Análise química - Determinação de perda ao fogo. Rio de Janeiro, 2004.

[11] FERREIRA FILHO, S. S., KAWAMOTO, P. H. "Efeito da oxidação química no processo de condicionamento e desidratação de lodos de estações de tratamento de água", In: IX Simpósio Luso Brasileiro de Engenharia Sanitária e Ambiental, Porto Seguro, 2000.

[12] FERREIRA FILHO, S. S. KAWAMOTO, P. H. "Cinética de processos de oxidação química aplicados em engenharia sanitária e ambiental”, In: IX Simpósio Luso Brasileiro de Engenharia Sanitária e Ambiental, Rio de Janeiro, ABES, 2000.

[13] ASSOCIAÇÃO BRASILEIRA DE NORMAS TÉCNICAS. NBR NM 53 - Agregado graúdo - Determinação de massa específica, massa específica aparente e absorção de água. Rio de Janeiro, 2009.

[14] ASSOCIAÇÃO BRASILEIRA DE NORMAS TÉCNICAS. NBR NM 45 - Agregados - Determinação da massa unitária e do volume de vazios. Rio de Janeiro, 2006.

[15] ASSOCIAÇÃO BRASILEIRA DE NORMAS TÉCNICAS. NBR NM 30. Agregado miúdo - Determinação da absorção de água. Rio de Janeiro, 2003.

[16] ASSOCIAÇÃO BRASILEIRA DE NORMAS TÉCNICAS. NBR NM 46. Agregados - Determinação do material fino que passa através da peneira 75 um, por lavagem. Rio de Janeiro, 2003.

[17] ASSOCIAÇÃO BRASILEIRA DE NORMAS TÉCNICAS. NBR 9781 - Peças de Concreto para Pavimentação. Especificação e Métodos de Ensaio. Rio de Janeiro, 2013.

[18] ASSOCIAÇÃO BRASILEIRA DE NORMAS TÉCNICAS. NBR 13279 -Argamassa para assentamento e revestimento de paredes e tetos - Determinação da resistência à tração na flexão e à compressão. Rio de Janeiro, 2005.

[19] ASSOCIAÇÃO BRASILEIRA DE NORMAS TÉCNICAS. NBR 9778 - Argamassa e concreto endurecidos - Determinação de absorção de água por imersão - Índice de vazios e massa específica. Rio de Janeiro, 1987.

[20] RICHTER, C. A. Tratamento de Lodos de Estações de Tratamento de Água. São Paulo, Edgard Blucher, 2001.

[21] PORTELLA, K.F., ANDREOLI, C.V., HOPPEN, C., et al., "Caraterização Físico-Química do Lodo Centifugado da Estação de Tratamento de Água Passaúna - Curitiba - PR", In: 22 Congresso Brasileiro De Engenharia Sanitária Ambiental. Joinvile, ABES, 2003.

[22] ASSOCIAÇÃO BRASILEIRA DE NORMAS TÉCNICAS. NBR NM 137 -Argamassa e concreto Água para amassamento e cura de argamassa e concreto de cimento Portland. Rio de Janeiro, 1997.

[23] HOPPEN, C., PORTELLA, K.F., ANDREOLI, C. V. "Uso de Lodo de ETA na Produção de Matriz de Concreto", In: Lodo de Estações de Tratamento de Água - Gestão e Perspectivas Tecnológicas. cap. 15, pp. 562 - 610. Curitiba, SANEPAR, 2013.

[24] TAFAREL, N. F., MACIOSKI, G., CARVALHO, K. Q., et al., "Avaliação das propriedades do concreto devido à incorporação de lodo de estação de tratamento de água", Matéria (UFRJ), v. 21, pp. 974-986, 2016.

[25] OLIVEIRA, N. S. Estudo de Secagem do Lodo de Estação de Tratamento de Água, Universidade Federal do Paraná, 2010.

[26] BIDONE, F., SILVA, A. P., MARQUES, D. D. "Lodos Produzidos nas Estações de Tratamento de Água (ETAs): Desidratação em Leitos de Secagem e Codisposição em Aterros Sanitários". In: Resíduos Sólidos do Saneamento: Processamento, Reciclagem e Disposição Final. cap. 9. pp. 215 - 244. Rio de Janeiro: ABES, 2001. 
[27] ANDREOLI, C. V., MOTTA, A. C. V., FERNANDES, C. V. S., et al., "Disposição Final de Lodos de Estações de Tratamento de Água”, In: Lodo de Estações de Tratamento de Água - Gestão e Perspectivas Tecnológicas. cap. 2. pp. 68 -130. Curitiba, SANEPAR, 2013.

[28] PINHEIRO-ALVES, M. T., GOMÀ, F., JALALI, S. "Um Cimento mais Sustentável Frente a um Ataque Severo por Sulfatos". In: $3 o$ Congresso Nacional da Construção, Universidade de Coimbra. Coimbra, Portugal, 2007.

[29] HOPPEN, C. Reciclagem de Lodo de ETA Centrifugado na Construção Civil, Método Alternativo para Preservação Ambiental. Universidade Federal do Paraná, 2004.

[30] PAIXAO, L. C. C., YOSHIMURA, H. N., ESPINOSA, D. C. R., et al., "Efeito da incorporação de lodo de ETA contendo alto teor de ferro em cerâmica argilosa", Cerâmica [online]. v.54, n.329 pp.63-76. 2008.

[31] MEDEIROS, M. H. F., SOUZA, D. J., HOPPE FILHO, J., et al., "Resíduo de cerâmica vermelha e fíler calcário em compósito de cimento Portland: efeito no ataque por sulfatos e na reação álcali-sílica", Matéria (Rio J.) [online]. v.21, n.2, pp.282-300, 2016.

[32] KAOSOL, T. "Reuse Water Treatment Sludge for Hollow Concrete Block Manufacture", Energy Research Journal., v. 1, n. 2, pp. 131-134, 2010.

[33] BENLALLA, A., ELMOUSSAOUITI, M., DAHHOU, M., et al.,"Utilization of Water Treatment Plant Sludge in Structural Ceramics Bricks", Applied Clay Science. v. 188, pp. 171 - 177, 2015.

[34] KIZINIEVIČ, O., ŽURAUSKIENÈ, R., KIZINIEVIČ, V., et al., "Utilization of Sludge Waste from Water Treatment for Ceramic Products”, In: Construction and Building Materials, v. 41, pp. 464 - 473, 2013.

[35] MEHTA, P. K., MONTEIRO, P. J. M. Concreto: Estruturas, Propriedades e Materiais, São Paulo, Pini, 1994. 